PROF. STEVEN JOHNSON (Orcid ID : 0000-0002-5114-5862)

Article type : Research Paper

Breeding systems in Drosera

RESEARCH PAPER

\title{
Breeding systems of floral colour forms in the Drosera cistiflora
} species complex

Caitlin G. von Witt ${ }^{\mathrm{a}}$, Bruce Anderson ${ }^{\mathrm{b}}$, Ian N. Durbach ${ }^{\mathrm{c}, \mathrm{d}}$ and Steven D. Johnson ${ }^{\mathrm{a}^{*}}$

a School of Life Sciences, University of KwaZulu-Natal, Private Bag X01, Scottsville, Pietermaritzburg, 3209, South Africa

${ }^{b}$ Department of Botany and Zoology, Stellenbosch University, Private Bag X1, Matieland, 7602, South Africa

${ }^{\mathrm{c}}$ Centre for Research into Ecological and Environmental Modelling, University of St Andrews, St Andrews, KY16 9LZ, Scotland

${ }^{\mathrm{d}}$ Centre for Statistics in Ecology, the Environment, and Conservation, Department of Statistical Sciences, University of Cape Town, Rondebosch, 7701, South Africa

* Correspondence. E-mail: Johnsonsd@ukzn.ac.za

Telephone: +27332605148

This article has been accepted for publication and undergone full peer review but has not been through the copyediting, typesetting, pagination and proofreading process, which may lead to differences between this version and the Version of Record. Please cite this article as doi: $10.1111 / \mathrm{plb} .13159$

This article is protected by copyright. All rights reserved 


\section{Abstract}

- Variation in plant breeding systems has implications for pollinator-mediated selection on floral traits and the ecology of populations. Here we evaluate pollinator contribution to seed production, self-compatibility and pollen limitation in different colour forms of Drosera cistiflora sensu lato (Droseraceae). These insectivorous perennial plants are endemic to fynbos and renosterveld vegetation in the Cape Floristic Region of South Africa and the species complex includes five floral colour forms (pink, purple, red, white and yellow), some of which are known to be pollinated by beetles.

- Controlled hand-pollination experiments were conducted in 15 populations of D. cistiflora s.1. (2-4 populations per floral colour form) to test whether the colour forms vary in their degree of selfcompatibility and their ability to produce seeds through autonomous self-fertilisation.

- Yellow-flowered forms were highly self-incompatible, while other floral colour forms exhibited partial self-compatibility. Seed set resulting from autonomous selfing was very low, and pollinator dependence indices were high in all populations. Since hand cross pollination resulted in greater seed set than open pollination in 13 of the 15 populations, we inferred that seed production is generally pollen-limited.

- Drosera cistiflora s.l. typically exhibits high levels of pollinator dependence and pollen limitation. This is unusual among Drosera species worldwide and suggests that pollinators are likely to mediate strong selection on attractive traits such as floral colour and size in D. cistiflora s.l. These results also suggest that the colour forms of D. cistiflora s.l. which are rare and threatened are likely to be vulnerable to local extinction if mutualisms were to collapse indefinitely.

Keywords: Seed production; hopliine beetle pollination; pollen limitation; pollinator dependence; selection; self-compatibility 


\section{INTRODUCTION}

Animal pollinators are known to visit approximately $88 \%$ of all flowering plant species (Ollerton et al. 2011) and reduced pollinator visitation may directly compromise plant seed production (Lundgren et al. 2016). However, for most plants it is still unclear to what extent their seed production is reliant on pollinators and how frequently it is limited by pollen receipt. Breeding system experiments using controlled hand-pollinations are consequently important for unravelling the degree of ecological dependence of plants on pollinator visits. Such information is of conservation significance since pollinator-dependent species are vulnerable to local extirpation of pollinators (Bond 1994; Pauw 2007). This is of particular concern in biodiversity hotspots (sensu Mittermeier et al. 1998) and in fire-prone environments such as the Cape Floristic Region (Rebelo 1987; Anderson et al. 2014).

Intraspecific variation in floral traits is common among plants and usually represents recent ongoing evolutionary divergence among populations (Herrera et al 2006; Moeller and Geber 2005). A classic example is flower colour which often varies both within populations and among populations (Narbona et al. 2018). The extent to which floral colour polymorphism may be linked with variation in breeding system traits is mostly unknown. This is in contrast to other floral traits such as flower size which are often strongly correlated with variation in breeding systems (c.f. Wyatt 1984; Dart et al. 2012). Inter-population variation in outcrossing rates is common in plant species and is attributed mainly to ecological factors (Whitehead et al. 2018), but could also reflect intra-specific variation in various breeding system components, such as self-incompatibility and degree of autogamy (Herrera et al 2001; Dart et al. 2012).

An apparent paradox among plants is that many species with specialised pollination systems also possess mechanisms for selfing (Wessinger and Kelly 2018). However, the association between specialisation and selfing can often be explained in terms of reproductive assurance where the ability to self may be strongly selected for in pollinator-dependent species where specialisation increases the risks of pollination failure (Fenster and Martén-Rodríguez 2007), especially if they are short-lived and dependent on seed for recruitment (Bond 1994). The ability to self will confer an immediate fitness advantage if levels of inbreeding depression are not high (Lloyd 1992; Barrett and Harder 1996; Herrera et al. 2001; Kalisz and Vogler 2003; Moeller and Geber 2005; Sciligo 2009; Rodger and Johnson 2013). Furthermore, delayed selfing may also mitigate some of the costs associated with inbreeding by utilising pollen and ovules which were not going to contribute towards reproduction through outcrossing (Barrett and Eckert 1990; Vogler and Kalisz 2001; Barrett 2003; Ashman et al. 2004; Sciligo 2009). In general, short-lived plants and those that otherwise inhabit unstable environments are most likely to exhibit selfing strategies (Cruden 1977; 
Lloyd and Webb 1986; Herrera et al. 2001; Sciligo 2009). Self-incompatible plants often have a relatively high likelihood of pollen limitation and seed production reduction as a result of pollinator failure because their own pollen does not contribute to fertilisation (Larson and Barrett 2000). This problem is expected to be less severe in self-compatible species that are pollinator-dependent.

Pollen limitation is thought to play an important role in determining floral phenotype because it should generate strong selection for secondary sexual traits that favour more effective pollinators and higher visitation rates (Kiester et al. 1984; Knight et al. 2005; Trunschke et al. 2017). In contrast, primarily selfpollinating species usually limit resource investment in floral display by having small flowers (Guerrant 1989; Dart et al. 2012) and fewer pollen grains per ovule (Cruden 1977). Strong selection by pollinators, because of pollen limitation combined with phenotype-dependent fitness differences among individuals, may accelerate speciation rates when pollinators vary geographically (Kay and Sargent 2009), as suggested by a correlation between high levels of pollen limitation and species richness (Vamosi et al. 2006). However, two meta-analyses (Anderson et al. 2014; Rodger and Ellis 2016) focussed on the Greater Cape Floristic Region (GCFR) and one focussed on the Brazilian Atlantic rainforest (Wolowski et al. 2014) did not find evidence that these biodiverse regions were characterised by high levels of pollen limitation.

We assess the breeding systems of the Drosera cistiflora L. species complex, to determine how different floral colour forms within the complex vary in terms of pollinator dependence, ability to self-pollinate and pollen-limitation. Drosera cistiflora s.l. belongs to the cosmopolitan carnivorous plant family Droseraceae. Although little is known about pollination in Drosera, some previous studies suggest that they often have a very low dependence on pollinators for reproduction with many being facultatively autogamous and reproducing primarily through self-pollination (Murza et al. 2006; Sciligo et al. 2007; Sciligo 2009; Cross et al. 2018). Flowers are nectarless with pollen as the only reward (Murza and Davis 2003; Cross et al. 2018) and a variety of different flower visitors have been recorded including bees, flies and beetles (see Wilson 1995; Murza and Davis 2005; Murza et al. 2006; Anderson 2010). Low pollinator dependence is often associated with habitat ephemerality (Cruden 1977; Lloyd and Webb 1986; Herrera et al. 2001), and many Drosera species are reliant on seasonal wetlands for active growth with only a small window of opportunity for outcrossing to take place (Sciligo 2009). Only one monophyletic lineage of Drosera is known to have xenogamous members with self-incompatibility (Chen et al. 1997). Several authors have argued that selfing in Drosera is adaptive because it may reduce the conflict generated by capturing pollinators (Sciligo et al. 2007; Sciligo 2009; Jürgens et al. 2011). However, most studies suggest that pollinator capture is unlikely to be an important selective force in Drosera (Anderson and Midgley 2001; Murza et al. 2006; Anderson 2010). In a meta-analysis on Drosera pollinator-prey conflict, Anderson and Midgley (2001) found no evidence to suggest that Drosera species had evolved adaptations to specifically 
resolve this putative conflict, while Anderson (2010) found that D. cistiflora s.l. never captures its pollinators. The ability of numerous Drosera species to reproduce asexually (via stolons, older leaves that take root when they touch the ground, scale leaves or gemmae in pygmy sundews, and/or tuber offshoots (see D'Amato 1998) may make many of them even less reliant on pollinators in the short term.

We hypothesised that, unlike the small-flowered Drosera species which typically self-pollinate, the largeflowered forms in the $D$. cistiflora species complex would show high pollinator dependence. To date, it has been unknown whether the various floral colour forms of D. cistiflora s.l. are self-compatible and, if so, whether any self autonomously. It is also unknown whether natural seed production of the various forms is pollen-limited. Showy flowers, which are otherwise costly to the plant in both energy requirements and herbivory risk (Sletvold and Grindeland 2008), are only likely to be maintained by selection if they promote cross-pollination. We test the hypothesis of high levels of pollinator dependence in D. cistiflora s.l. by investigating the effects of pollination treatments on seed production in multiple populations of the five extant floral colour forms.

\section{MATERIALS AND METHODS}

\section{Study species}

The D. cistiflora species complex is endemic to moist habitats in the fynbos and renosterveld vegetation of the winter-rainfall Greater Cape Floristic Region of South Africa. Flowering of D. cistiflora s.l. occurs in the austral springtime, i.e. August-September (Trinder-Smith et al. 2006). D. cistiflora s.l. displays great variety in corolla colour, with six known floral colour forms - pink, purple, red, salmon pink, white and yellow (Fig. 1). Three of these forms (purple, red and yellow) are exceptionally rare and one (salmon pink) is extinct in the wild. More than one floral colour form can be found at some sites. Pink and white colours may occasionally intergrade at some sites, suggesting that this variation is a quantitative trait and reflects a single gene pool. However sympatric purple and red colour forms appear to be discrete, raising questions about whether flower colour at these sites is a polymorphism or an indication of distinct gene pools of different taxa. The cymose inflorescences presented 10-40 $\mathrm{cm}$ above ground level consist of 1-few large, dark-centred actinomorphic flowers (Obermeyer 1970) which are bowl-shaped, devoid of nectar (Goldblatt et al. 1998) and unscented to human olfaction (pers. obs). Each flower lasts 1-3 days. Pollinator dependence is suggested by strong herkogamy (Barrett 2003) (Fig. 1). Despite a report that plants can reproduce vegetatively, with plantlets developing from the succulent rootstock to form a clonal group 
(Gibson 2006), our experience is that clusters usually comprise groups of solitary plants and individuals may frequently be separated from conspecifics by a metre or more, indicating that recruitment occurs mainly or exclusively via seeds.

In their general investigation of pollination by hopliine (monkey) beetles in southern African petaloid geophytes, Goldblatt et al. (1998) suggested that D. cistiflora L. is primarily, and likely exclusively, pollinated by these beetles. This has been confirmed in a recent study (von Witt, 2020). Hopliine beetles are associated with flowers of a wide range of colours, with some evidence for differing colour preferences among species (Picker and Midgley 1996; Johnson and Midgley 2001; van Kleunen et al. 2007). All D. cistiflora s.l. floral colour forms have dark olive- or blue-green to grey floral centres (Fig. 1), and similar patterns of colour contrasts have been shown to increase visitation by hopliine beetles in irid geophytes (van Kleunen et al. 2007).

Drosera cistiflora L. is taxonomically classified within Drosera L. subgen. Drosera sect. Ptycnostigma Planch., largely using style morphology, a lack of stipules, thickened roots, corolla size and the presence of cauline leaves as delimitations (Schlauer 1996). Seine and Barthlott (1994) treated D. cistiflora L. as a single taxon in section Ptycnostigma, with radially symmetrical marginal tentacles in the cauline leaves and a chromosome number of $2 n=60$. However, in their phylogenetic analyses for Drosera, Rivadavia et al. (2003) suggest that there are two clades in D. cistiflora, characterised by chromosome numbers $2 n=40$ and $2 n=60$. In that study, chromosome numbers (sourced from Kondo and Olivier 1979 and Hoshi and Kondo 1998) were obtained from only two sources of plant material (namely "South Africa" and "c. 11km west of Port Elizabeth"). The D. cistiflora rbcL gene sequence was derived from a single voucher specimen, and flower colour was not specified. The study by Rivadavia et al. (2003) may therefore underestimate the number of operational taxonomic units in the D. cistiflora complex.

Drosera has not been comprehensively revised since Diels' (1906) classical monograph which treated $D$. cistiflora L. as having two varieties, namely D. cistiflora var. $\delta$. exilis Diels and D. cistiflora var. $\beta$. speciosa (Presl) Diels. Owing to variability of leaf size, shape, quantity, stem length, flower size and colour in the D. cistiflora species complex (Rivadavia 2000), a multitude of other varieties, and even some species-level splits, have been proposed (see Table S1). Of these, the D. cistiflora s.l. forms included in this study correspond to Drosera rubripetala Debbert, D. cistiflora var. $\beta$. rubra Thunberg or D. cistiflora var. $\beta$. speciosa (Presl) Diels (red flowers); D. violacea Willdenow, D. cistiflora var. $\beta$, violacea Thunberg or $D$. cistiflora var. violacea (Willdenow) Sonder (purple flowers with reflexed petals); D. cistiflora 'Purple West Coast' (purple crateriform corollas), and the typical D. cistiflora Linn. (pink, mauve or white flowers). Purple-flowered forms with reflexed and non-reflexed petals were grouped together for the study, based on 
striking similarities in petal colour: purple with a strongly metallic blue-green base. The yellow floral colour form, here provisionally named D. cistiflora 'Piketberg', was rediscovered in Piketberg by the first author and a local conservation group in 2008, having previously been known from a 1930 specimen housed in the Compton Herbarium under Drosera cistiflora L. One population of this form occurs within $1 \mathrm{~km}$ of a typical pink-flowered form of $D$. cistiflora s.l. with no signs of introgression. The distinct corolla colour and cup-like shape additionally indicate that it warrants taxonomic investigation. In the absence of adequate taxonomic resolution based on molecular, morphological and ecological factors, we treat $D$. cistiflora as a species complex for the purposes of this study.

\section{Study sites}

We selected 12 study sites that represent 15 populations (ranging from 19 to over 250 flowering plants, Table S2) of five colour forms of D. cistiflora s.1., three of which occurred in sympatry at three respective sites. The sampling included four populations of the pink-flowered form, two of the purple-flowered form (one with reflexed petals and one with crateriform corollas), three of the red-flowered form, three of the white-flowered form and three of the yellow-flowered form (Table S2). Voucher specimens for each population studied are housed in the Compton Herbarium (Table S2).

\section{Breeding system experiments}

To determine the degree of self-compatibility and capacity for autonomous self-fertilisation in D. cistiflora s.1., four treatments (bagged only, open pollination, hand self-pollination and hand cross-pollination) were applied to a minimum of eight plants per treatment (mean $=11.1$, range $=8-21$ ) per population (one flower per plant was treated). The bagged only treatment was applied to test for autonomous selfing. For this treatment, a fine bridal veil, mesh bag was suspended over a wire frame and placed over an unmanipulated D. cistiflora s.l. plant with a marked flower in bud stage to ensure that pollinators could not access it. The bag was removed after the flower had wilted. The open pollination treatment was applied to test for natural seed set, where pollinators had access to flowers throughout their development. These flowers were not bagged, hand-pollinated or manipulated in any way. The hand self-pollination treatment was applied to test for self-incompatibility. Here, a marked flower was bagged in bud and when the bud opened, the receptive stigma was pollinated using pollen from the same flower (flowers are strongly herkogamous, but, based on some overlap of pollen dehiscence and moist papillae on the stigma, do not appear to be completely protandrous). The flower was re-bagged to prevent subsequent pollinator-mediated contamination and the 
bag was removed after the flower had wilted. The hand cross-pollinated treatment was applied as a positive control. These flowers were emasculated in the bud phase prior to anther dehiscence, before being bagged to exclude pollinators. Once receptive, the stigma was pollinated using plucked stamens from a donor with dehiscent anthers from at least five metres away to avoid treating with pollen from within a possible genet, i.e. clonal group. The plant was re-bagged and the bag was removed once the flower had wilted. Experiments were conducted in 2009 and included a total of 335 bagged plants and 255 plants observed for natural seed set. Sample size per treatment group is given in Table S3.

Purple-flowered plants in Durbanville had anthers that appeared to be only partially formed and produced little to no pollen, and for this reason only natural seed set was recorded in this population. Likewise, there were too few fully-formed white flowers at Darling site 1 for treatments (i), (iii) and

(iv) to be performed.

For all treatments, mature seed capsules were collected and seeds counted under a dissecting microscope approximately 20 days later.

\section{Pollination indices}

Empirical mean values of seed set per flower were used to calculate all pollination indices to obtain independent pollinator dependence, self-incompatibility and pollen limitation indices, for each $D$. cistiflora s.l. population and for each floral colour form over all populations. An index of pollinator contribution to seed production was added to assess the degree of natural pollination without artificial pollen supplementation. Individuals not setting fruit were recorded as producing no seeds i.e. as zeroes. Whiteflowered populations at Darling 1, and pink and purple populations at Durbanville were excluded since only their natural seed set could be assessed.

\section{Pollinator contribution to seed production (PCS)}

To obtain a metric for PCS, we compared seed set from the 'bagged only' treatment, that tested for autonomous self-pollination, (i) with natural seed set (ii).

We computed PCS as: PCS $=1$ - autonomous self-pollination / open pollination. PCS varies from zero to one, with a total lack of pollinator contribution yielding a value of zero and a value of one defining maximum PCS. 


\section{Pollinator dependence (PD)}

The PD index compared seed set from the 'bagged only' treatment (i) with that arising from hand crosspollination (iv).

PD was computed as: PD = 1 - autonomous self-pollination / hand cross-pollination. Here, a value of zero indicates independence from pollinators, while a value of one indicates high dependence on pollinators. PD is modified from the commonly presented Index of Autofertility, AF (Lloyd and Schoen 1992), sensu Anderson et al. (2014).

\section{Self-incompatibility (SI)}

The degree of self-compatibility was determined by comparing seed set from the hand cross-pollination treatment (iv) to seed set from the hand self-pollination treatment (iii) [Lloyd 1965].

An index for SI was calculated as: SI = 1 - hand self-pollination / hand cross-pollination. Self-compatibility varies from zero to one and decreases as the index approaches a value of one, i.e. complete selfincompatibility.

\section{Pollen limitation (PL)}

PL was measured by comparing natural seed set through open pollination (ii) with seed set after hand crosspollination (iv) [modified from Larson and Barrett 2000], as follows: PL $=1$ - open pollination / hand cross-pollination. Pollen limitation is expressed as a number between zero and one, where complete pollen limitation equates to a value of one while a lack of pollen limitation yields a value of zero.

Confidence intervals (CI) for the indices were calculated using a bootstrap procedure in which the mean values, together with ratios and indices derived from the means, were computed for each of 1000 resampled datasets. The overall mean seed set for each treatment per floral colour form was generated as the sum of all weighted population means.

\section{Statistical analyses}

Data were analysed using generalised linear mixed models (GLMM) implemented in R (R Core Team 2018). The number of flowers setting fruit in a D. cistiflora s.l. population was assumed to be binomially distributed. Probability of setting fruit was modelled as being dependent on treatment, floral colour form, and population. The explanatory variables thus include categorical fixed effects for treatment and flower 
colour and a random effect for population. Note that for a study of plant genetic factors such as this, population (rather than site) is the experimental unit and thus most appropriate random effect level. As a result, two different colour populations occurring at the same site (at Darling 2 and Durbanville) are treated as separate levels rather than pooled into a common one. The linear dependency between the probability of setting fruit and explanatory variables was specified using a logit link function. The number of seeds per fruit was overdispersed relative to the expectation of a Poisson distribution (the variance exceeded the mean), and was thus modelled using a negative binomial distribution where the mean was dependent on treatment, floral colour form, and population. The explanatory variables thus included categorical fixed effects for treatment and flower colour and a random effect for population. Linear dependency was specified using a log link function. Following model fitting, the Tukey method was used to adjust for multiple comparisons in post hoc tests. Marginal means were obtained by back-transformation of values from the linear scale, resulting in asymmetric standard errors. In cases in which GLMMs for seed set did not run because of lack of variance (e.g. no fruits set for certain combinations of floral colour form and treatment effect), a single value of one seed was substituted (sensu Zuur et al. 2009), which also makes the test more conservative (Johnson et al. 2019).

Separate GLMMs were fitted for fruit set (proportion of flowers setting fruit) and seed set (number of seeds per fruit). Attempts to model seeds produced per flower suffered from estimation problems relating to overdispersion caused by the introduction of excess zeros induced by observations where no fruit was set. Pollination indices were based on empirical means for seeds per flower which allow us to use a single set of indices.

\section{RESULTS}

\section{Breeding system experiments}

Overall, fruit and seed production varied significantly among treatments (fruit: $\chi^{2}(3)=101.79, p<0.001$; seed: $\chi^{2}(3)=123.22, \mathrm{p}<0.001$ ) and D. cistiflora s.l. floral colour forms (fruit: $\chi^{2}(4)=32.80, \mathrm{p}<0.001$; seed: $\chi^{2}(4)=20.74, p<0.001$, with a significant interaction effect between treatment condition and floral colour form for seed production $\left(\chi^{2}=73.20, \mathrm{p}<0.001\right)$ [Figs $2 \mathrm{a}, \mathrm{b}$ ].

The effects of pollinator exclusion varied among floral colour forms, with purple- and yellow-flowered forms showing almost no fruit production after pollinator exclusion, as opposed to c. $25 \%$ of flowers 
setting fruit following this treatment in the pink-, red- and white-flowered forms (Fig. 2a). However, seed set arising from autonomous self-pollination was very low across all floral colour forms (Fig. 2b). Significant differences $(\mathrm{p}<0.001)$ in the marginal (model-adjusted) mean proportion of flowers that set fruit were found between the autonomous self-pollination (mean $=0.07,95 \% \mathrm{CI}=0.03-0.16$ ) and hand cross-pollination $($ mean $=0.94,95 \% \mathrm{CI}=0.84-0.98)$ treatments. Additionally, significantly $(\mathrm{p}<0.001)$ fewer seeds were set per fruit through autonomous selfing (mean $=28.47,95 \% \mathrm{CI}=18.19-44.54$ ) than hand cross-pollination (mean $=259.22,95 \% \mathrm{CI}=184.40-364.38$ ), with these differences being significant for all floral colour forms (all $\mathrm{p}<0.002)$ ).

Hand cross-pollinated flowers showed almost $100 \%$ fruit set in the case of the pink, red and white forms and c. $60 \%$ fruit set for the purple and yellow forms. Hand self-pollination yielded similar levels of fruit set to hand cross-pollination for all forms, except purple and yellow, which showed a significant decrease in fruit production for self-pollinated flowers (Table S3, Fig. 2a). Across all floral colour forms, fruit set in hand cross-pollinated flowers (mean $=0.94,95 \% \mathrm{CI}=0.84-0.98)$ was significantly $(\mathrm{p}=0.002)$ greater than that from hand self-pollination (mean $=0.70,95 \% \mathrm{CI}=0.48-0.85$ ). Similarly, seed set per fruit after hand self-pollination (mean $=159.81,95 \% \mathrm{CI}=110.69-230.72)$ was significantly $(\mathrm{p}=0.003)$ less than after hand cross-pollination (mean $=259.22,95 \% \mathrm{CI}=184.40-364.38$ ) overall, with these differences being driven by significant differences in pink- and yellow-flowered forms (pink: $\mathrm{z}=3.47, \mathrm{p}=0.003$; yellow: $\mathrm{z}=$ $3.20, \mathrm{p}=0.007$; other colours: $\mathrm{z}<1.03, \mathrm{p}>0.735$ )

Levels of natural fruit set in open-pollinated flowers were similar to those following hand self-pollination (Table S3, Fig. 2a). Natural fruit set and seed set per fruit were particularly low for the purple- and yellowflowered forms (Table S3, Figs 2a, b).

Mean fruit set was significantly $(\mathrm{p}<0.001)$ higher in hand cross-pollinated flowers (mean $=0.94,95 \%$ CI $=0.84-0.98$ ) than in open-pollinated flowers (mean $=0.63,95 \% \mathrm{CI}=0.46-0.78$ ). Hand cross-pollinated flowers also set significantly $(\mathrm{p}<0.001)$ more seed per fruit $($ mean $=259.22,95 \% \mathrm{CI}=184.40-364.38)$ than those in open pollination treatments (mean $=149.82,95 \% \mathrm{CI}=105.98-211.79)$. These differences were driven by significant differences in purple $(\mathrm{z}=6.18, \mathrm{p}<0.001)$, yellow $(\mathrm{z}=4.40, \mathrm{p}<0.001)$ and pink $(\mathrm{z}=3.96, \mathrm{p}<0.001)$ floral colour forms (other colours: $\mathrm{z}<0.82, \mathrm{p}>0.845)$.

Across all treatments, purple- and yellow-flowered plants had significantly $(\mathrm{p}<0.011)$ lower proportion fruit set than did pink-, red- and white-flowered forms. They also produced significantly $(0.004<\mathrm{p}<$ 0.025 ) fewer seeds per fruit than did red-and white-flowered forms (Figs 2a, b), with pink-flowered forms occupying an intermediate position in the case of seed set. However, there were no significant differences 
among the colour forms (all pairwise $\mathrm{p}>0.550$ ) in seeds per fruit arising from the hand cross-pollination treatment. Post hoc tests for the significance of differences between treatments applied to the various $D$. cistiflora s.1. floral colour forms are provided in tables S8, S9, S10 and S11.

\section{Pollination indices}

\section{Pollinator contribution to seed production (PCS)}

Indices of overall PCS for each floral colour form, calculated using means weighted according to population sample sizes, ranged from 0.67 to 1.00 among forms (Table 1). PCS was highest in white, red and purple floral colour forms in an ascending order of magnitude (Table 1). The indeterminate PCS index associated with yellow-flowered forms (Table 1) is a function of the indeterminate PCS of the Piketberg 2 population. Here, no seed was set through either autonomous self-pollination or open pollination. Sitespecific PCS indices (Table 2) for yellow-flowered populations at Piketberg 1 (0.40) and Piketberg 3 (1.00) however show that the yellow-flowered form exhibits some degree of PCS.

\section{Pollinator dependence (PD)}

PD indices indicated that all floral colour forms are highly dependent on pollinators for seed set and that autonomous selfing contributes little to reproductive output (Table 1). Pink-flowered forms had the lowest dependence on pollinators ( 0.89$)$ and purple-flowered forms were completely dependent on pollinators (PD $=1.00$, Table 1). Similarly, at the population level, no population had a PD index of less than 0.83 (Table S4).

\section{Self-incompatibility (SI)}

White, red, purple and pink floral colour forms were partially self-incompatible, with SI indices ranging from 0.29 (white) - 0.53 (pink) [Table 1]. Yellow-flowered forms displayed high levels of selfincompatibility (0.82), since plants in only one out of three populations set seed from self-pollen, and hand self-pollination yielded lower seed set than hand cross-pollination in all three populations. The degree of self-incompatibility varied substantially among populations of different colours [range $=0.18$ (pink, Riverlands NR) - 1.00 (yellow, Piketberg 2 \& 3), Table S5]. Self-incompatibility also varied between populations of the same colour, particularly between pink-flowered populations. For example, the SI index of 0.18 at Riverlands NR suggests high selfing capability, while another pink population had an SI index of 0.87 , suggesting low selfing capability (Table S5).

This article is protected by copyright. All rights reserved 


\section{Pollen limitation (PL)}

PL indices ranged from 0.07 in red-flowered forms (least pollen-limited) to 1.00 in purple-flowered forms (complete pollen limitation). Seed production of pink-, purple- and yellow-flowered forms was the most pollen-limited (Table 1). Despite plenty of variance in pollen limitation between floral colour forms (Table 1), variance within each form was low (Table S6).

\section{DISCUSSION}

This study demonstrates that all floral colour forms of Drosera cistiflora s.1. are highly dependent on pollinators for seed production and range from partially self-compatible to almost completely selfincompatible (Table 1, Fig. 2). In addition, seed production in most forms appears to be strongly pollenlimited (Tables 1 and S7). These results contrast starkly with the general view that Drosera species are often autogamous selfers with low levels of dependence on pollinators (cf. Murza et al. 2006; Sciligo et al. 2007; Sciligo 2009; Cross et al. 2018).

The partial genetic self-incompatibility and spatial separation of the anthers and stigmas of D. cistiflora s.1. plants are likely to be contributing factors to their dependence on pollinators. Relatively high natural seed set, in combination with low seed set from autonomous selfing, indicates high pollinator contribution to seed production in red (98\%), white (96\%) and pink (67\%) floral colour forms (Tables 1 and S4). However, extremely low natural seed set was found in two yellow-flowered populations, namely Piketberg 2 \& 3 (Table 2). The higher fruit and seed set after hand-crosses (Table S4) suggests a shortage of effective pollinators in both of these yellow-flowered populations and the possibility of a mutualism collapse. von Witt (2020) correspondingly recorded unusually low pollinator visitation in these two yellow-flowered populations. It is uncertain why pollinators in these populations performed so poorly and whether this situation is temporary or more permanent. It is possible that very recent fires (seven months prior to flowering) adversely affected pollinator communities through mortality or shortages of food plants for insects (Dafni et al. 2013). The risks of pollinator failure in D. cistiflora s.l. are mitigated in the short-term by the fact that $D$. cistiflora s.l. is perennial and can reproduce vegetatively (Bond 1994); however, sexual reproduction is considered important for the long-term persistence of species (Wuerth et al. 2018). Remarkably low natural fruit and seed set was also found in the two purple-flowered populations (Table S3), and purple-flowered plants at Darling 2 had low seed production even after hand-crossing (Table S4). Infertility may be a mechanism behind overall low fruit and seed set in these purple- and yellow-flowered populations, which is evidenced at Durbanville by the lack of pollen production by purple flowers. Infertility could occur as a result of limited S-alleles (Reinartz and Les 1994), inbreeding depression 
(Eckert 2001; Charlesworth and Willis 2009) or alternatively as a result of a lack of vigour of $F_{1}$ and/or subsequent filial generations (Johansen-Morris and Latta 2006) produced through hybridisation of sympatrically growing floral colour forms. Purple-flowered populations grew at two of three sites in this study which had sympatric $D$. cistiflora s.l. floral colour forms where introgression was possible. Although we did not observe plants in these populations with intermediate floral colour phenotypes, their mode of colour inheritance is not known; consequently the lack of apparently intermediate forms cannot exclude the possibility of introgression. Preliminary experiments suggest partial genetic barriers between purple and red floral colour forms (von Witt 2020), but further investigation into these potential mechanisms is required.

One further possible reason for low seed set per fruit in some colour forms could be a reduced number of ovules. We did not count ovules in flowers, but found no significant overall differences among colour forms in the number of seeds per fruit arising from hand cross-pollination (Table S10, Fig 2b), suggesting that ovule number is unlikely to be the main factor accounting for differences in natural seed set among colour forms.

Relative to hand self-pollination, hand cross-pollination gave rise to significantly greater fruit set in purple and yellow D. cistiflora s.1. floral colour forms (Table S7, Fig. 2a) and in significantly greater seed set per fruit in pink and yellow colour forms (Table S9, Fig 2b). Although this suggests that some colour forms of D. cistiflora s.l. are fully or partially self-incompatible, it does not preclude the possibility that the plants may be self-compatible with high levels of early inbreeding depression at the seed development stage evident in some colour forms. The self-incompatibility index for yellow-flowered forms was particularly high $(82 \%$, Table 1), with two populations at Piketberg appearing to be completely self-incompatible (Table S5). Low pollinator visitation and high (90\%) pollinator dependence (Table 1) in yellow-flowered populations renders them particularly vulnerable to reproductive failure.

All D. cistiflora s.l. floral colour forms displayed some degree of pollen limitation and PL indices were particularly high in pink-, purple- and yellow-flowered forms (Table 1). This indicates that seed set is considerably limited by a paucity of cross-pollen reaching the stigmas. It is therefore expected that there should be strong selection acting on traits that make the plants more attractive to pollinators or enhance the efficiency of pollen transfer (Knight et al. 2005). Although the flowers of D. cistiflora s.l. are nectarless and odourless, their large size, bowl shape, showy colours and conspicuous orange-yellow anthers may make them easily visible. Floral characters such as these are commonly found in hopliine beetle-pollinated flowers (van Kleunen et al 2007), where it has been proposed that the beetles visit the flowers in search of food and mates (Goldblatt et al. 1998) in response to visual rather than olfactory cues (Steiner 1998). Likewise, the elongated stems increase flower height, which may have evolved for pollinator attraction 
(Anderson and Midgley 2001; Anderson 2010; Jürgens et al. 2015), since elevated D. cistiflora s.l. flowers received more visits by pollinators than flowers of experimentally shortened plants (Anderson 2010).

Usually pollen limitation is calculated by comparing natural seed set with that arising from supplemental cross-pollination of open flowers (Larson and Barrett 2000; Knight et al. 2006) and is conventionally confirmed when plants with pollen supplementation produce more seed than control plants (Bierzychudek 1981; Ashman et al. 2004; Knight et al. 2005). Since our hand-pollinated flowers were bagged, they were protected from seed predators, in contrast to the open-pollinated flowers that were not bagged and thus exposed to seed predators. Consequently, if seed predators account for lower seed production in openpollinated flowers, then pollen limitation may be overestimated in this study. However, this is unlikely since we observed minimal seed predation when dissecting fruits and this did not vary in an obvious manner between treatments. Some populations had slightly negative values for the PL metric, suggesting higher natural seed set than when flowers were hand-crossed. Slight negative values may reflect no real difference from zero. Alternatively, these could have resulted from the fact that hand-pollinated flowers were bagged after crosses were made and hence open-pollinated flowers may have had more mating opportunities than hand-pollinated flowers in some instances.

Supplemental hand-pollination with pure cross-pollen can also be considered unnatural and artificially boost seed set (Aizen and Harder 2007). By comparing natural seed set with seed set in both self- and cross-pollinated flowers (Table S3, Fig. 2b), we could determine if pollen limitation is due only to the quantity of pollen or if pollen quality also matters. The significantly greater seed set through hand crosspollination than through open pollination in D. cistiflora s.1. colour forms overall (Table S7) indicates that seed set may be limited by pollen quantity (Aizen and Harder 2007). However, hand cross-pollinations transferred pure intraspecific cross-pollen only while pollinators usually deposit pollen mixtures which can include self-pollen, cross-pollen, and pollen from other plant species (Fang and Huang 2013). Open pollination also did not usually result in more seed than hand- selfing experiments (Table S3, Figure 2b), suggesting that much of it could potentially be the result of pollinator-mediated selfing (pollen movement within a flower mediated by pollinators, see Lloyd 1992; Anderson et al. 2003). The general increase in hand-crossed seed set relative to natural and hand-selfing (Table S3, Figure 2b) is further evidence that seed production is also being limited by pollen quality. In summary, pollen quality as well as quantity limitation appear to be acting in D. cistiflora s.l., thereby further emphasising the importance of effective pollinator movement in ensuring the seed production of each floral colour form. Rodger and Ellis (2016) accordingly found evidence suggesting that pollen quality was an important contributor towards pollen limitation in pollinator-dependent plants in the GCFR.

This article is protected by copyright. All rights reserved 
Striking differences in breeding system biology among the floral colour forms included in this study suggest that these forms differ in more than just floral colour pigmentation. Strong pollinator dependence and pollen limitation also suggest that colour may be under pollinator-mediated selection and that floral colour variation could reflect adaptations to different pollinators. Further experimental research is required to test the adaptive significance of floral colour variation and whether pollinators may be contributing towards apparent divergent evolutionary trajectories within the D. cistiflora complex (cf . Tao et al. 2018). Several examples of co-occurring floral colour forms, namely purple and red, purple and pink, purple and white, and red and white, without the formation of obvious fertile hybrids further suggest that some, but probably not all, of these forms deserve recognition at the species level. Some sympatric forms also differ in subtle vegetative characters (von Witt 2020), suggesting that their floral colour differences may represent diverged lineages, and not a simple colour polymorphism with Mendelian inheritance. Future research into reproductive isolation barriers and the phylogeny of the complex will provide useful insights into the taxonomic and affiliated conservation statuses of some of these rare colour forms (cf. Tao et al. 2018)

From a conservation management perspective, there is a need to study the environmental basis for pollination failure. Statistical models that include measurements of fragment size, population size, population density, population isolation, vegetation type, post-fire successional stage, soil fertility, pollinator abundance and diversity, and urbanisation offer promise to explain patterns of natural seed set in D. cistiflora s.l. floral colour forms. Such information would supplement the limited existing research on the role of pollinators in long-term maintenance of habitat integrity and may improve understanding of the requirements for effective environmental management strategies.

\section{Acknowledgements}

We thank the private landowners that allowed access to plant populations, Cape Nature for permitting research at Riverlands Nature Reserve, and SANBI and the Bolus and Compton herbaria for granting access to databases and collections. The study was supported by the National Research Foundation of South Africa (Grant 46372 to SDJ). 


\section{Supporting Information}

Additional Supporting Information may be found online in the supporting information tab for this article:

Table S1. Drosera cistiflora L.: synonyms and valid names.

Table S2. Flower colour, locality and number of Drosera cistiflora s.l. flowers studied.

Table S3. A comparison of marginal model means (and asymmetric 95\% CI values) calculated for proportion of flowers that set fruit and number of seeds set per fruit.

Table S4. Pollinator dependence (PD) values for populations.

Table S5. Self-incompatibility (SI) values for populations.

Table S6. Pollen limitation (PL) values for populations.

Table S7. Posthoc (Tukey) tests of differences in proportion of fruit and seed set between treatments.

Table S8. Posthoc (Tukey) tests of differences in fruit and seed set between Drosera cistiflora s.l. floral colour forms

Table S9. Posthoc (Tukey) tests of differences in seed set per fruit between treatments for each Drosera cistiflora s.l. floral colour form

Table S10. Posthoc (Tukey) tests of differences in seed set per fruit between Drosera cistiflora s.l. floral colour forms for each treatment 


\section{REFERENCES}

Aizen M.A., Harder L.D. (2007) Expanding the limits of the pollen-limitation concept: effects of pollen quantity and quality. Ecology, 88, 271-281.

Anderson B. (2010) Did Drosera evolve long scapes to stop their pollinators from being eaten? Annals of Botany, 106, 653-657.

Anderson B., Allsopp N., Ellis A.G., Johnson S.D., Midgley J., Pauw A., Rodger, J. (2014) Biotic Interactions. In: Allsopp N., Colville J.F., Verboom A.G., Cowling R.M. (Eds), Ecology and evolution of fynbos: understanding megadiversity. Oxford University Press, Oxford, UK.

Anderson B., Midgley J.J. (2001) Food or sex; pollinator-prey conflict in carnivorous plants. Ecology Letters, 4, 511-513.

Anderson B., Midgley J.J., Stewart B.A. (2003) Facilitated selfing offers reproductive assurance: a mutualism between a hemipteran and carnivorous plant. American Journal of Botany, 90, 1009-1015.

Ashman T.L., Knight T.M., Steets J.A., Amarasekare P., Burd M., Campbell D.R., Dudash M.R., Johnston M.O., Mazer S.J., Mitchell R.J., Morgan M.T., Wilson W.G. (2004) Pollen limitation of plant reproduction: ecological and evolutionary causes and consequences. Ecology, 85, 2408-2421.

Barrett S.C.H. (2003) Mating strategies in flowering plants: the outcrossing-selfing paradigm and beyond. Philosophical Transactions of the Royal Society B: Biological Sciences, 358, 991-1004.

Barrett S.C.H., Eckert C.G. (1990) Variation and evolution of mating systems in seed plants. In: Kawano S. (Ed.), Biological approaches and evolutionary trends in plants. Academic Press, London, UK, pp 229254.

Barrett S.C.H., Harder L.D. (1996) Ecology and evolution of plant mating. Trends in Ecology and Evolution, 11, 73-79.

Bierzychudek P. (1981) Pollinator limitation of plant reproductive effort. The American Naturalist, 117, 838-840.

Bond W.J. (1994) Do mutualisms matter? Assessing the impact of pollinator and disperser disruption on plant extinction. Philosophical Transactions of the Royal Society B: Biological Sciences, 344, 83-90.

Charlesworth D., Willis, J.H. (2009) The genetics of inbreeding depression. Nature Reviews: Genetics, 10, 783-796.

Chen L., James S.H., Stace H.M. (1997) Self-incompatibility, seed abortion and clonality in the breeding systems of several western Australian Drosera species (Droseraceae). Australian Journal of Botany, 45, 191-201.

Cross A.T., Davis A.R., Fleischmann A., Horner J.D., Jürgens A., Merritt D.J., Murza G.L., Turner S.R. (2018) Reproductive biology and pollinator-prey conflicts. In: Ellison A.M., Adamec L. (Eds), 
Carnivorous plants: physiology, ecology, and evolution. Oxford University Press, New York, USA, pp 294-313.

Cruden R.W. (1977) Pollen-ovule ratios: a conservative indicator of breeding systems in flowering plants. Evolution, 31, 32-46.

D'Amato P. (1998) The savage garden: cultivating carnivorous plants. Ten Speed Press. Berkeley, California, USA.

Dafni A., Izhaki I., Ne'eman G. (2013) The effect of fire on biotic interactions in Mediterranean Basin ecosystems: pollination and seed dispersal. Israel Journal of Ecology and Evolution, 58, 235-250.

Dart S.R., Samis K.E., Austen E., Eckert C.G. (2012) Broad geographic covariation between floral traits and the mating system in Camissoniopsis cheiranthifolia (Onagraceae): multiple stable mixed mating systems across the species' range? Annals of Botany, 109, 599-611.

Diels L. (1906) "Droseraceae". In: Engler A. (Ed.), Das Pflanzenreich. Wilhelm Engelmann, Leipzig, Germany, pp 1-136.

Eckert C.G. (2001) The loss of sex in clonal plants. Evolutionary Ecology, 15, 501-520.

Fang Q., Huang S. (2013) A directed network analysis of heterospecific pollen transfer in a biodiverse community. Ecology, 94, 1176-1185. doi:10.1890/12-1634.1.

Fenster C.B., Martén-Rodríguez S. (2007) Reproductive assurance and the evolution of pollination specialisation. International Journal of Plant Sciences, 168, 215-228.

Gibson R. (2006) The stunning red-flowered Drosera cistiflora in the wild and in cultivation. Carnivorous Plant Newsletter, 35, 70-73.

Goldblatt P., Bernhardt P., Manning, J.C. (1998) Pollination of petaloid geophytes by monkey beetles (Scarabaeidae: Rutelinae: Hopliini) in Southern Africa. Annals of the Missouri Botanical Garden, 85, $215-230$.

Goldblatt P., Manning J.C. (2000) Cape plants, a conspectus of the Cape flora of South Africa. Strelitzia 9. National Botanical Institute, Pretoria.

Guerrant E.O. Jr (1989) Early maturity, small flowers and autogamy: a developmental connection? In: Bock J.H., Linhart Y.B. (Eds), The evolutionary ecology of plants. Westview Press, Boulder, Colorado, USA, pp 61-84.

Herrera, C.M., Castellanos, M.C., Medrano, M. (2006) Geographical context of floral evolution: towards an improved research programme in floral diversification. In: Harder L.D., Barrett S.C.H. (Eds), Ecology and evolution of flowers. Oxford University Press, Oxford, UK, pp 278-294.

Herrera C.M., Sánchez-Lafuente A.M., Medrano M., Guitian J., Cerda X., Rey P. (2001) Geographical variation in autonomous self-pollination levels unrelated to pollinator service in Helleborus foetidus (Ranunculaceae). American Journal of Botany, 88, 1025-1032.

This article is protected by copyright. All rights reserved 
Hoshi Y., Kondo K. (1998) A chromosome phylogeny of the Droseraceae by using CMA-DAPI fluorescent banding. Cytologia, 63, 329-339.

Johansen-Morris A.D., Latta R.G. (2006) Fitness consequences of hybridisation between ecotypes of Avena barbata: hybrid breakdown, hybrid vigor, and transgressive segregation. Evolution, 60, 1585-1595.

Johnson S.D., Butler H.C., Robertson A.W. (2019) Breeding systems in Cyrtanthus (Amaryllidaceae): variation in self-sterility and potential for ovule discounting. Plant Biology, ISSN 1435-8603.

Johnson S.D., Midgley J.J. (2001) Pollination by monkey beetles (Scarabaeidae: Hopliini): do colour and dark centres of flowers influence alighting behaviour? Environmental Entomology, 30, 861-868.

Jürgens A., Sciligo A.R., Witt T., El-Sayed A.M., Suckling M. (2011) Pollinator-prey conflict in carnivorous plants. Biological reviews, 87, 602-615.

Jürgens A., Witt T., Sciligo A., El-Sayed A.M. (2015) The effect of trap colour and trap-flower distance on prey and pollinator capture in carnivorous Drosera species. Functional Ecology, 29, 1026-1037.

Kalisz S., Vogler D.W. (2003) Benefits of autonomous selfing under unpredictable pollinator environments. Ecology, 84, 2928-2942.

Kay K.M., Sargent R.D. (2009) The role of animal pollination in plant speciation: integrating ecology, geography, and genetics. Annual Review of Ecological Systems, 40, 637-656.

Kiester A.R., Lande R., Schemske D.W. (1984) Models of coevolution and speciation in plants and their pollinators. The American Naturalist, 124, 220-243.

Knight T.M., Steets J.A., Ashman T.L. (2006) A quantitative synthesis of pollen supplementation experiments highlights the contribution of resource reallocation to estimates of pollen limitation. American Journal of Botany, 93, 271-277.

Knight T.M., Steets J.A., Vamosi J.C., Mazer S.J., Burd M., Campbell D.R., Dudash M.R., Johnston M.O., Mitchell R.J., Ashman T.L. (2005) Pollen limitation of plant reproduction: pattern and process. Annual Review of Ecology Evolution and Systematics, 36, 467-497.

Kondo K., Olivier M.C. (1979) Chromosome numbers of four species of Drosera (Droseraceae). Annals of the Missouri Botanical Garden, 66, 584-587.

Larson B.M.H., Barrett S.C.H. (2000) A comparative analysis of pollen limitation in flowering plants. Biological Journal of the Linnean Society, 69, 503-520.

Lloyd D.G. (1965) Evolution of self-compatibility and racial differentiation in Leavenworthia (Cruciferae). Contributions from the Gray Herbarium of Harvard University, 195, 3-134.

Lloyd D.G. (1992) Self- and cross-fertilisation in plants. II. The selection of self-fertilisation. International Journal of Plant Sciences, 153, 370-380.

Lloyd D.G., Schoen D.J. (1992) Self- and cross-fertilisation in plants. I. Functional dimensions. International Journal of Plant Sciences, 153, 358-369.

This article is protected by copyright. All rights reserved 
Lloyd D.G., Webb C.J. (1986) The avoidance of interference between the presentation of pollen and stigmas in angiosperms. 1. Dichogamy. New Zealand Journal of Botany, 24, 135-162.

Lundgren R., Totland Ø., Lázaro A. (2016) Experimental simulation of pollinator decline causes community-wide reductions in seedling diversity and abundance. Ecology, 97, 1420-1430.

Mittermeier R.A., Myers N., Thomsen J.B., Da Fonseca G.A.B., Olivieri S. (1998) Biodiversity hotspots and major tropical wilderness areas: approaches to setting conservation priorities. Conservation Biology, 12, 516-520.

Moeller D.A., Geber M.A. (2005) Ecological context of the evolution of self-pollination in Clarkia xantiana: population size, plant communities and reproductive assurance. Evolution, 59, 786-799.

Murza G.L., Davis A.R. (2003) Comparative flower structure of three species of sundew (Droseraceae: Drosera anglica, D. linearis and D. rotundifolia) in relation to breeding system. Canadian Journal of Botany, 81, 1129-1142.

Murza G.L., Davis A.R. (2005) Flowering phenology and reproductive biology of Drosera anglica. Botanical Journal of the Linnean Society, 147, 417-426.

Murza G.L., Heaver J.R., Davis A.R. (2006) Minor pollinator-prey conflict in the carnivorous plant, Drosera anglica. Plant Ecology, 184, 43-52.

Narbona, E., Wang, H., Ortiz, P.L., Arista, M., Imbert, E. (2018) Flower colour polymorphism in the Mediterranean Basin: occurrence, maintenance and implications for speciation. Plant Biology, 20, 8-20.

Obermeyer A.A. (1970) Droseraceae. Flora of Southern Africa, 13, 187-201.

Ollerton J., Winfree R., Tarrant S. (2011) How many flowering plants are pollinated by animals? Oikos, 120, 321-326.

Pauw A. (2007) Collapse of a pollination web in small conservation areas. Ecology, 88, 1759-1769.

Picker M., Midgley J.J. (1996) Pollination by monkey beetles (Coleoptera: Scarabaeidae: Hopliini): flower and colour preferences. African Entomology, 4, 7-14.

$\mathrm{R}$ Core Team (2018) R: A language and environment for statistical computing. R Foundation for Statistical Computing, Vienna, Austria. ISBN 3-900051-07-0, http://www.R-project.org/.

Rebelo A.G. [Ed.] (1987) Preliminary synthesis of pollination biology in the Cape flora. National Scientific Programmes Unit: CSIR, SANSP Report, 141, 265.

Reinartz, J.A. and Les, D.H. (1994) Bottleneck-induced dissolution of self-incompatibility and breeding system consequences in Aster furcatus (Asteraceae). American Journal of Botany, 81, 446-455.

Rivadavia F. (2000) Endless carnivorous plants in Cape Town, South Africa. Carnivorous Plant Newsletter, 29, 42-25.

Rivadavia F., Kondo K., Kato M., Hasebe M. (2003) Phylogeny of the sundews, Drosera (Droseraceae), based on chloroplast rbcL and nuclear $18 \mathrm{~S}$ ribosomal DNA sequences. American Journal of Botany, 90, $123-130$.

This article is protected by copyright. All rights reserved 
Rodger J.G., Ellis A.G. (2016) Distinct effects of pollinator dependence and self-incompatibility on pollen limitation in South African biodiversity hotspots. Biology Letters, 12, 20160253. doi:10.1098/rsbl.2016.0253.

Rodger J.G., Johnson S.D. (2013) Self-pollination and inbreeding depression in Acacia dealbata: can selfing promote invasion in trees? South African Journal of Botany, 88, 252-259.

Schlauer J. (1996) A dichotomous key to the genus Drosera L. (Droseraceae). Carnivorous Plant Newsletter, 25, 67-88.

Sciligo A.R. (2009) Food or sex: which would you choose? Pollinator-prey conflict and reproductive assurance in New Zealand Drosera. PhD Thesis. Lincoln University, New Zealand.

Sciligo A.R., Sulllivan J.J., Jesson L.K., Witt T., Jürgens A., Hale R.J., Newstrom L. (2007) Is selfing more advantageous than sex in Drosera due to the pollinator-prey conflict? ESA/SER Joint Meeting, San Jose McEnery Convention Centre, California, USA.

Seine R., Barthlott W. (1994) Some proposals on the infrageneric classification of Drosera L. Taxon, 43, 583-589.

Sletvold N., Grindeland J.M. (2008) Floral herbivory increases with inflorescence size and local plant density in Digitalis purpurea. Acta Oecologica, 34, 21-25.

Steiner, K.E. (1998) Beetle pollination of peacock moraeas (Iridaceae) in South Africa. Plant Systematics and Evolution, 209, 47-65.

Tao, Z.B., Ren, Z.X., Bernhardt, P., Liang, H., Li, H.D., Zhao, Y.H., Wang, H., Li, D.Z. (2018) Does reproductive isolation reflect the segregation of color forms in Spiranthes sinensis (Pers.) Ames complex (Orchidaceae) in the Chinese Himalayas? Ecology and Evolution, 8, 5455-5469.

Trinder-Smith T., Maytham Kidd M., Anderson F. (2006) Wild Flowers of the Table Mountain National Park. Botanical Society of South Africa, Cape Town, South Africa.

Trunschke J., Sletvold N., Ågren J. (2017) Interaction intensity and pollinator-mediated selection. New Phytologist, 214, 1381-1389.

Vamosi J.C., Knight T.M., Steets J.A., Mazer S.J., Burd M., Ashman T.L. (2006) Pollination decays in biodiversity hotspots. Proceedings of the National Academy of Sciences of the United States of America, 103, 956-961.

van Kleunen M., Nänni I., Donaldson J.S., Manning J.C. (2007) The role of beetle marks and flower colour on visitation by monkey beetles (Hopliini) in the Greater Cape Floral Region, South Africa. Annals of Botany, 100, 1483-1489.

Vogler D.W., Kalisz S. (2001) Sex among the flowers: the distribution of plant mating systems. Evolution, 55, 202-204.

von Witt C.G. (2020) Pollination and geographical divergence in flower colour of the Drosera cistiflora species complex. PhD Dissertation. University of Kwazulu-Natal, South Africa.

This article is protected by copyright. All rights reserved 
Wessinger C.A., Kelly J.K. (2018) Selfing can facilitate transitions between pollination syndromes. The American Naturalist, 191, 582-594.

Whitehead, M.R., Lanfear, R., Mitchell, R.J., Karron, J.D. (2018) Plant mating systems often vary widely among populations. Frontiers in Ecology and Evolution, 6, 38.

Wilson P. (1995) Pollination in Drosera tracyi: selection is strongest when resources are intermediate. Evolutionary Ecology, 9, 382-396.

Wolowski M., Ashman T.L., Freitas L. (2014) Meta-analysis of pollen limitation reveals the relevance of pollination generalisation in the Atlantic forest of Brazil. PLoS ONE, 9, e89498. doi:10.1371/journal.pone.0089498.

Wuerth D.G., Eusemann P., Trouillier M., Buras A., Burger A., Wilmking M., Roland C.A., Juday G.P., Schnittler M. (2018) Environment drives spatiotemporal patterns of clonality in white spruce (Picea glauca) in Alaska. Canadian Journal of Forest Research, 48, 1577-1586.

Wyatt R. (1984) The evolution of self-pollination in granite outcrop species of Arenaria (Caryophyllaceae). I. Morphological correlates. Evolution 38, 804-816.

Zuur A., Ieno E.N., Walker N., Saveliev A.A., Smith G.M. (2009) Mixed effects models and extensions in ecology with R. Springer-Verlag, New York, USA. 
Table 1. Overall indices of pollinator contribution to seed production (PCS), pollinator dependence (PD), self-incompatibility (SI) and pollen limitation (PL) for the five floral colour forms of Drosera cistiflora s.l. Indices for each colour form were calculated using empirical means weighted by sample size. PCS values for the yellow form were indeterminate, since seed set from both autonomous self-pollination and open pollination equal zero in Piketberg 2 (see main text for full explanation). 95\% CI values are given in parentheses.

\begin{tabular}{lllll}
\hline \hline $\begin{array}{l}\text { Drosera } \\
\text { cistiflora } \text { s.l. } \\
\text { floral colour } \\
\text { form }\end{array}$ & PCS & PD & SI & PL \\
\hline Pink & $0.67(0.51 ; 0.86)$ & $0.89(0.81 ; 0.94)$ & $0.53(0.37 ; 0.65)$ & $0.66(0.42 ; 0.72)$ \\
Purple & $1.00(1.00 ; 1.00)$ & $1.00(1.00 ; 1.00)$ & $0.41(-0.54 ; 1.00)$ & $1.00(1.00 ; 1.00)$ \\
Red & $0.98(0.96 ; 1.00)$ & $0.98(0.97 ; 1.00)$ & $0.32(-0.03 ; 0.57)$ & $0.07(-0.22 ; 0.28)$ \\
White & $0.96(0.90 ; 1.00)$ & $0.97(0.92 ; 1.00)$ & $0.29(0.06 ; 0.49)$ & $0.19(-0.05 ; 0.39)$ \\
Yellow & Indet. $(-5.76 ; 1.00)$ & $0.90(0.67 ; 1.00)$ & $0.82(0.53 ; 1.00)$ & $0.92(0.82 ; 0.98)$ \\
\hline
\end{tabular}


Table 2. Pollinator contribution to seed production (PCS) values showing empirical means $\pm \mathrm{SE}$ of seed set from autonomous self-pollination and open pollination for each Drosera cistiflora s.l. population, where $\mathrm{PCS}=1-$ Seed set through autonomous self-pollination/ Open pollination. Sample size (n) indicates number of plants treated (one flower per plant). Indeterminate refers to the instance where seed set from both autonomous self-pollination and open pollination equal zero.

\begin{tabular}{llllll}
\hline \hline $\begin{array}{l}\text { Drosera cistiflora } \text { s.l. } \\
\text { flower colour } \\
\text { and site }\end{array}$ & $\begin{array}{l}\text { Autonomous } \\
\text { self-pollination }\end{array}$ & $\mathrm{n}$ & $\begin{array}{l}\text { Open } \\
\text { pollination }\end{array}$ & $\mathrm{n}$ & PCS \\
\hline Pink (Darling 6) & $7.50 \pm 4.12$ & 8 & $102.54 \pm 26.76$ & 11 & 0.93 \\
Pink (Darling 7) & $68.13 \pm 19.64$ & 15 & $196.56 \pm 39.55$ & 16 & 0.65 \\
Riverlands NR & $2.38 \pm 1.31$ & 8 & $36.90 \pm 3.16$ & 10 & 0.94 \\
\hline Purple (Darling 2) & $0.00 \pm 0.00$ & 10 & $0.10 \pm 0.10$ & 20 & 1.00 \\
\hline Red (Darling 1) & $0.00 \pm 0.00$ & 8 & $445.00 \pm 33.44$ & 20 & 1.00 \\
Red (Darling 2) & $2.31 \pm 2.31$ & 13 & $180.48 \pm 10.91$ & 21 & 0.99 \\
Red (Darling 3) & $8.64 \pm 4.98$ & 14 & $159.33 \pm 14.78$ & 15 & 0.95 \\
\hline White (Darling 4) & $26.62 \pm 18.34$ & 8 & $506.00 \pm 60.73$ & 15 & 0.95 \\
White (Darling 5) & $0.00 \pm 0.00$ & 8 & $184.00 \pm 35.34$ & 20 & 1.00 \\
\hline Yellow (Piketberg 1) & $27.20 \pm 24.83$ & 10 & $45.00 \pm 20.72$ & 10 & 0.40 \\
Yellow (Piketberg 2) & $0.00 \pm 0.00$ & 8 & $0.00 \pm 0.00$ & 20 & Indet. \\
Yellow (Piketberg 3) & $0.00 \pm 0.00$ & 8 & $0.29 \pm 0.17$ & 21 & 1.00 \\
\hline
\end{tabular}




\section{Figure captions}

Fig. 1 Floral colour forms in the Drosera cistiflora species complex: pink (A), purple (B), white (C), red (D), yellow (E) and salmon pink (F). Scale bars $=1 \mathrm{~cm}$. Photo (F) by Ignace Janssens.

Fig. 2 Comparison of the effects of autonomous self-pollination, open pollination, hand self-pollination and hand cross-pollination on each Drosera cistiflora s.l. floral colour form. Values represent marginal model mean (and asymmetric standard error) proportions of flowers setting fruit (A) and number of seeds per fruit (B). 


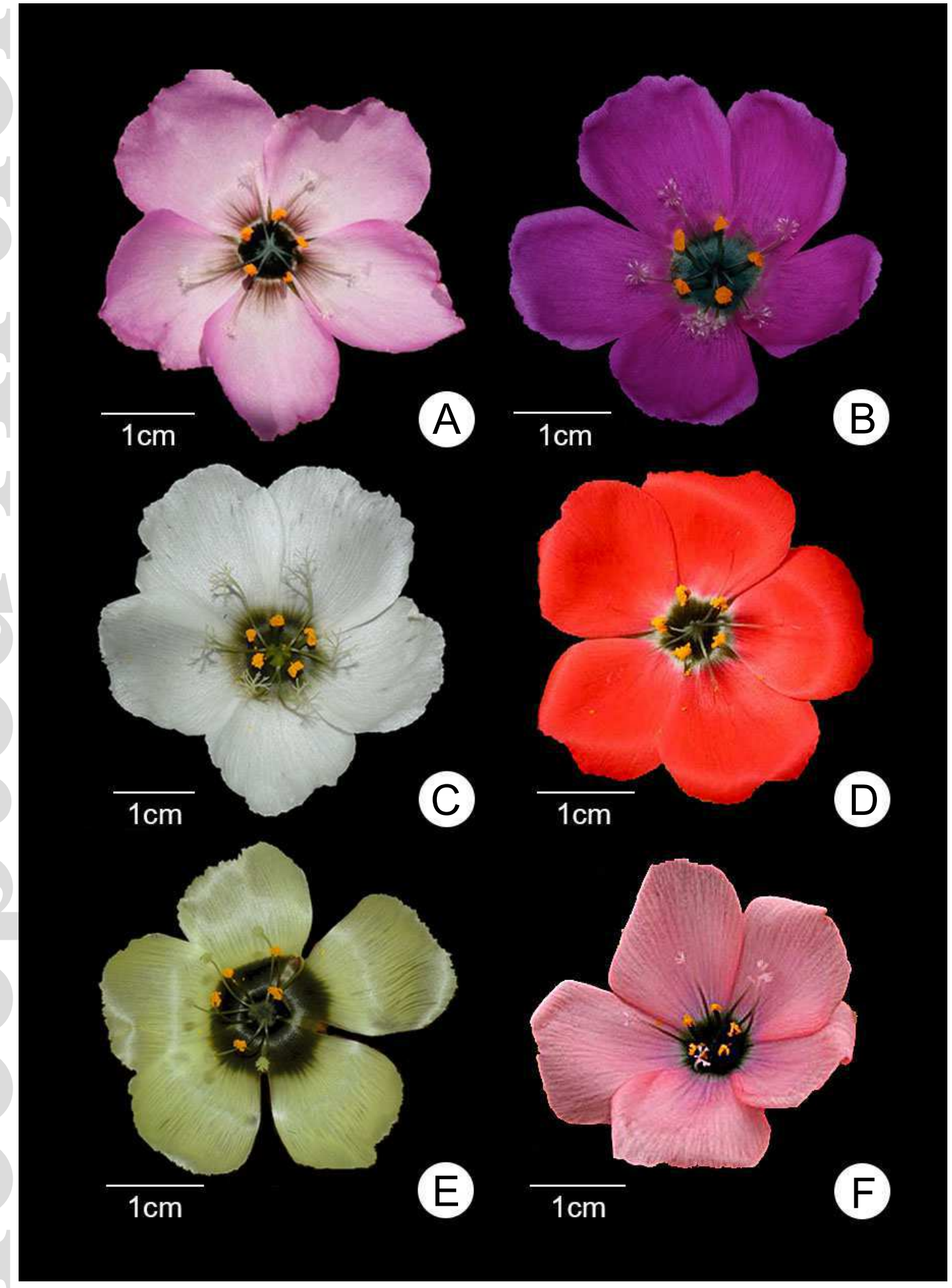

This article is protected by copyright. All rights reserved 

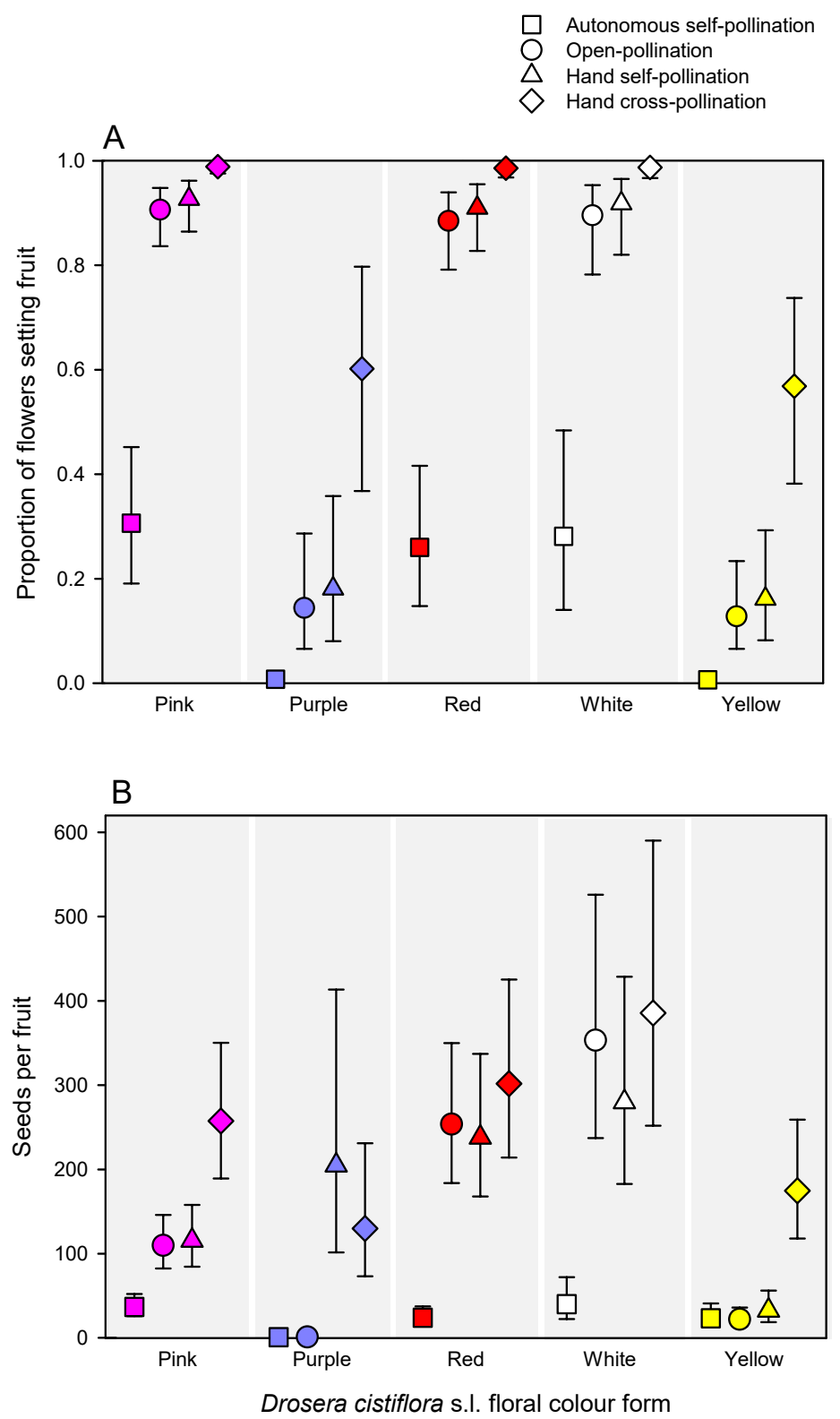

This article is protected by copyright. All rights reserved 